Ismail Sérageldin, June Taboroff (sous la direction), Culture et développement en Afrique, Actes de la conférence internationale, organisée au siège de la Banque mondiale, Washington, 2-3 avril 1992, Washington, ESD, N 1, Série Débats, 1994.

Mahaman Tidjani Alou

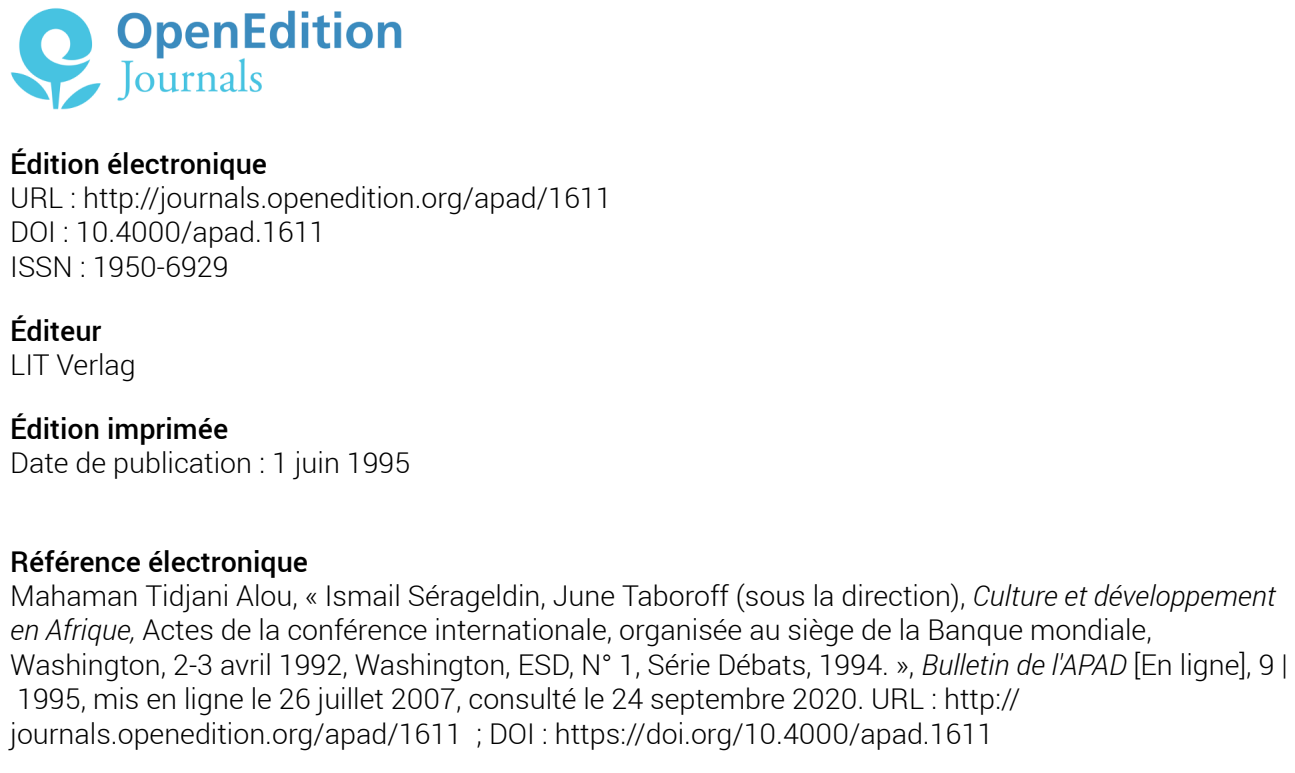

Ce document a été généré automatiquement le 24 septembre 2020.

Bulletin de l'APAD 


\section{Ismail Sérageldin, June Taboroff (sous la direction), Culture et développement en Afrique, Actes de la conférence internationale, organisée au siège de la Banque mondiale, Washington, 2-3 avril 1992, Washington, ESD, N 1 , Série Débats, 1994.}

Mahaman Tidjani Alou

1 Le thème de la culture dans son rapport au développement connaît ces dernières années un regain d'intérêt, suffisamment d'intérêt en tout cas pour susciter un regard anthropologique sur la question. Actes d'un colloque de la Banque mondiale, l'ouvrage édité sous la direction de I. Sérageldin et J. Taboroff est d'abord axé sur les préoccupations actuelles des Etats africains. Il poursuit la réflexion engagée vers la fin des années 70 sur les rapports entre culture et développement, avec un regard qui ne change pas fondamentalement la nature des débats.

2 Le livre est bâti autour de plusieurs thèmes principaux :

- Théorie culturelle et pratique du développement

- Culture et société civique

- Les institutions culturelles

- La protection de l'environnement historique construit

- Développement, archéologie et environnement

- Le développement économique : culture, cause et conséquence. 
3 Pour chacun de ces thèmes, des sous-thèmes ont été identifiés et traités par des spécialistes.

On peut lire ce livre de deux manières :

- si l'on choisit de le lire en diagonale, on peut retenir les différents résumés qui jalonnent l'ouvrage au niveau de chacune de ses articulations. En effet, les éditeurs ont produit pour chacun des thèmes retenus par le colloque une synthèse des interventions qui permet de rapporter l'essentiel de ce qui a été dit lors des séances. Par ailleurs, on peut trouver à la fin de l'ouvrage non seulement une synthèse des interventions mais aussi un rapport de chaque séance thématique. En outre, chaque contribution est précédée d'un résumé qui condense l'essentiel des propos de son auteur.

- une autre manière de lire l'ouvrage, qui est plus fastidieuse, va dans le sens d'une lecture intégrale. Si dans le premier mode de lecture, on peut se permettre de lire tous les résumés et les rapports de synthèse, dans ce cas-ci, on peut se permettre d'être plus sélectif en ne focalisant l'attention que sur les articles qui suscitent un intérêt particulier. Là, les genres sont divers. Ils vont des approches les plus théoriques (Wildavski par exemple, p.155) aux approches par cas rendant compte d'expériences particulières (Etounga-Manguélé, p.243), ou de situations historiques spécifiques (Putman sur l'Italie, p.37 ou Mading Deng sur le Soudan, p. 515).

5 En ce qui concerne le fond du livre, il est clair que les contributions n'ont pas le même intérêt au regard de la socio-anthropologie. C'est pourquoi nous proposons de limiter la présentation de l'ouvrage aux plus significatives d'entre elles. Non pas que les autres ne soient pas intéressantes, mais elles nous semblent beaucoup moins directement axées sur nos préoccupations en raison des sujets qu'elles abordent et qui concernent les institutions culturelles, l'archéologie ou la protection des sites historiques, etc.

De toutes les contributions retenues, celles de Klitgaard parait être celle qui situe le mieux les problèmes posés par les rapports entre culture et développement. Le titre de sa contribution est en lui-même suggestif et en dit long sur les impasses actuelles. "Prendre en compte la culture : oui, mais comment ?" Klitgaard constate qu"'on sait depuis au moins une quarantaine d'années qu'il faut prendre en compte la culture dans le processus de développement". Mais ce qu'on ne sait pas, reconnait l'auteur, c'est comment la prendre en compte scientifiquement (méthodes et données) ou pratiquement. Pour Klitgaard, dans les années 1990 (le colloque s'est déroulé en 1992), le "comment" va se placer au centre des préoccupations : comment les peuples des pays en développement peuvent-ils améliorer leurs conditions de vie en prenant la culture en compte et comment les sciences sociales, telles que l'anthropologie, peuvent-elles être d'une aide pratique? Pourquoi, bien que l'on étudie les cultures depuis plus d'un siècle, n'existe-t-il pas de théories bien développées, de directives pratiques et de liens interprofessionnels entre ceux qui étudient la culture et ceux qui décident et gèrent la politique de développement? L'objet de Klitgaard est justement d'examiner les explications possibles. Cette contribution se termine par des annexes diverses relatives aux variables culturelles à prendre en compte, sur les facteurs culturels dans le développement rural en Afrique centrale et bien d'autres choses encore.

Le texte de A. Wildavski explore pour sa part une problématique plus pointue. Partant de l'approche de Mary Douglas sur la culture (les valeurs et les croyances sont rattachées aux rapports sociaux qu'ils légitiment), il émet l'hypothèse que le développement économique durable est déterminé par l'éloignement "du fatalisme et de la hiérarchie monopolistique" et simultanément par le rapprochement vers "un 
individualisme conjugué à la hiérarchie ouverte". Dans la mesure où les besoins et les ressources sont des constructions sociales, pour Wildavski, les contraintes qui pèsent sur le développement tiennent aux modes de vie. Si l'on tient compte de la diversité des situations propres aux espaces sociaux, et partant des modes de vie, on voit les complexités que peut induire l'hypothèse de Wildavski dont l'idée centrale est "qu'aucun progrès théorique ou pratique ne sera possible tant que les cultures seront assimilées aux pays et qu'on en déduira qu'il ne peut y avoir qu'une seule culture par pays et par région", et d'ajouter que "seule une conception pluraliste de la culture, c'est à dire une conception qui considère les cultures comme autant de modes de vie différents, peut déboucher sur des conseils utiles".

8 Si les apports que nous venons de passer en revue se spécifient par leur caractère théorique, ceux qui suivent sont plutôt des études de cas, inspirées de terrains africains. Mamadou Dia présente les éléments d'une étude dont il annonçait la parution en 1993 (ce qui veut dire qu'elle est maintenant disponible) et qui est consacrée aux "Pratiques indigènes de gestion : leçons pour la gestion de l'Afrique des années 90". Sur la base de dix huit cas, il analyse la manière dont les valeurs et les motivations socioculturelles ont été liées aux succès ou l'échec de divers projets et institutions dans les secteurs informel et formel. Dia préconise l'utilisation des cas réussis pour mieux gérer les projets et les programmes de réformes traitant de développement institutionnel et de gestion. Mais à l'étape actuelle du débat, on en reste encore aux suggestions. Le texte $\mathrm{C}$. Bryant s'inscrit dans ce même cadre de recherche.

9 Etounga-Manguélé pour sa part, avance d'un cran puisque son texte fait part de son expérience, à travers le cabinet qu'il dirige et qui oriente son action vers l'organisation de séminaires sur l'ajustement culturel, destinés aux dirigeants d'entreprises. Le texte proposé est sommaire. Mais on peut en déduire toute la difficulté qu'il a à mesurer les résultats d'une action de formation en terme de changement dans la conduite et le comportement.

10 S.S. Nyang, dont le texte a été coupé à l'impression en son premier paragraphe, examine, à une échelle plus macrosociale, la dynamique du changement culturel en Afrique. Il identifie les forces régissant le maintien de l'autonomie culturelle dans la société africaine post-coloniale et cherche à établir si le processus de développement a favorisé ou gêné leurs actions. Pour Nyang les économistes et autres experts des sciences sociales n'ont guère prêté attention au rôle et à la place de la culture dans le développement, voyant dans celui-ci un processus universel et unilinéaire dans lequel les hommes passent de systèmes économiques agraires à des systèmes économiques industrialisés. Nyang souligne les bases matérielles, institutionnelles et axiologiques de la culture. Il fait valoir que les décideurs africains ont échoué ou réussi dans la mise en œuvre de leurs programmes en fonction de la manière dont ils ont traité la culture, la religion ou l'identité culturelle. Pour Nyang, tenir compte des facteurs culturels est la condition pour parvenir à un développement d'inspiration locale, ancré dans l'histoire, la culture et la psychologie des peuples africains.

11 On remarquera que de manière générale les démarches ne changent pas et tournent toujours sur le mode analyse-recommandation. Les analyses proposées se basent souvent sur le constat de l'échec des politiques mises en œuvre, ou encore sur leurs effets sur le plan culturel. Elles débouchent ensuite sur les recommandations qui doivent guider la mise en œuvre des politiques de développement. 
12 La culture est omniprésente dans ces analyses, qui restent malheurement pauvres en conclusions opératoires. Il y a certes des avancées indiscutables, plus diversifiées quant aux tentatives d'opérationnalisation des propositions, mais les questions de départ subsistent. On continue toujours à rechercher le contenu de la notion de culture : comment la prendre en compte dans les politiques de développement en général et les projets de développement en particulier? Et si on la prend en compte, qu'est-ce qui permettrait de garantir des résultats pertinents en termes de développement? On sait tellement peu ce que ce dernier mot veut dire. Ainsi, le débat ouvert sur les rapports entre culture et développement se présentent plus comme un pari que comme une panacée. D'où cette tendance qu'ont les auteurs à survaloriser la variable culturelle comme gage de succès d'une politique de développement alors qu'elle n'est qu'un élément parmi tant d'autres, dont on sait qu'elle a donné dans la pratique les résultats les plus divers.

13 Les questions qui se posent alors sont nombreuses : l'ouverture tous azimuts du monde contemporain est-elle compatible avec la valorisation des cultures locales des pays du Sud et leur prise en compte dans les politiques de développement? Les politiques de développement actuellement portées par les Etats ne vont-elles pas à l'encontre des sub-cultures locales, qui sont souvent plus proches des réalités sociologiques? Or la culture fait surtout référence à la culture nationale, dont on sait pourtant qu'elle cherche à se façonner. Tout ceci pour dire qu'il reste du chemin à parcourir. Tout porte à croire qu'il plane encore des incertitudes que seule une meilleure connaissance des réalités sociologiques pourrait permettre d'amoindrir.

On pourrait conclure cette note par une réflexion de M. Arkoun, un des rapporteurs du Colloque : "Je suis convaincu qu'il faut nous orienter vers une anthropologie appliquée, fondée non seulement sur une érudition et une accumulation d'informations sur les groupes socioculturels, mais aussi sur des critères concrets. Des solutions seraient ainsi proposées pour un développement fondé sur l'histoire culturelle ou sur les nouveaux besoins des groupes concernés et non plus seulement de la société globale, telle qu'elle est perçue par des fonctionnaires technocrates ou des politiciens, comme ce fut le cas dans plusieurs pays du tiers-monde depuis les indépendances"(p. 138).

On voit bien que s'il faut considérer les besoins des groupes, ce sera à chaque projet de développement d'imposer sa propre dimension culturelle. 